\title{
A Meta-Analysis of Peer-Support Interventions for Adults With Diabetes
}

\author{
Michael E. Jobansen, MD, MS, Editorial Fellow \\ Ann Fam Med 2016;14(6):iii. doi:10.1370/afm.1998
}

T The Annals of Family Medicine encourages readers to develop a learning community of those seeking to improve health care and health through enhanced primary care. You can participate by conducting a RADICAL journal club. RADICAL is an acronym for Read, Ask, Discuss, Inquire, Collaborate, Act, and Learn. It also indicates the need to engage diverse participants in thinking critically about, and then acting on, important issues affecting primary care. ${ }^{1}$

\section{HOW IT WORKS}

In each issue, the Annals selects an article and provides discussion tips and questions. We encourage you to post a summary of your journal club's conversation. (Open the article and click on "TRACK Comments: Submit a response.") Details are available at http:// www.AnnFamMed.org/site/AJC/.

\section{CURRENT SELECTION}

\section{Article for Discussion}

Patil S, Ruppar T, Koopman RJ, et al. Peer support interventions for adults with diabetes: a meta-analysis of hemoglobin $A_{1 c}$ outcomes. Ann Fam Med. 2016;14(6):540-551.

\section{Discussion Tips}

Systematic reviews and meta-analyses are observational studies that provide an overview of a literature. However, analysis of these types of studies requires additional skills over those needed to analyze randomized controlled trials. This article offers an opportunity to investigate positive and negative aspects of this type of study in assessing the effect of peer support interventions on the narrow but summative outcome of glycosylated hemoglobin.

\section{Discussion Questions}

- What is a systematic review? What is a metaanalysis? How are they related? What are their primary weaknesses?

- What was the research question for this review?
- Was the scope of the question appropriate (too broad or narrow)? How adequate was the search? - What kind of important studies might have been missed due to scope or search criteria?

- What is PRISMA? ${ }^{2}$ What are the benefits and downsides of following this reporting structure?

- What is heterogeneity and why is it an important concept in systematic reviews and meta-analysis? - How is heterogeneity measured in this study?

- What is publication bias? Why is this an important concept in systematic reviews and meta-analyses?

- How is this investigated in the study?

- What is a standard mean difference? Why was this the primarily reported outcome?

- What are the main findings? Was an important level of heterogeneity identified, and how does that affect your interpretation of the findings?

- How did the results change when investigated by different subgroups?

-What is an ecological fallacy? How might individual patient data (instead of trial level) have strengthened the study findings?

- What are the strengths and weaknesses of hemoglobin $\mathrm{A}_{1 \mathrm{c}}$ as an outcome measure? ? $^{3}$ Why do you think the authors investigated hemoglobin $\mathrm{A}_{1 \mathrm{c}}$ ?

- Were the decreases in hemoglobin $\mathrm{A}_{1 \mathrm{c}}$ "clinically meaningful"? Were they durable? How long was the follow-up of the included studies?

- Are the patients in the primary studies comparable to patients in your practice?

- Will this article change your practice? If so, how?

\section{References}

1. Stange KC, Miller WL, McLellan LA, et al. Annals Journal Club: It's time to get RADICAL. Ann Fam Med. 2006;4(3):196-197. http:// annfammed.org/cgi/content/full/4/3/196.

2. Liberati A, Altman DG, Tetzlaff J, et al. The PRISMA statement for reporting systematic reviews and meta-analyses of studies that evaluate healthcare interventions: explanation and elaboration. BMJ. 2009;339:b2700.

3. Yudkin John S, Lipska Kasia J, Montori Victor M. The idolatry of the surrogate. BMJ. 2011;343:d7995. 